\title{
Bagaimana Anak Muda Memahami Kesenjangan Ekonomi?
}

\author{
Victorius Didik Suryo Hartoko ${ }^{1,2}$, Thomas Dicky Hastjarjo ${ }^{2}$ E Avin Fadilla Helmi ${ }^{2}$ \\ ${ }^{1}$ Fakultas Psikologi Universitas Sanata Dharma, \\ ${ }^{2}$ Fakultas Psikologi Universitas Gadjah Mada
}

\begin{abstract}
This study aimed to find out how young adult understand the economic disparity issue and whether ideas related to that problem had authoritarianism and materialism inclinations. The study was done to group of university students age $18-30$ years old. There were 295 people participating in the study. It utilized survey with open ended questionnaire to figure out participants' feelings and thoughts toward economic disparity. Subjects also filled out authoritarianism and materialism scales. The result showed that subjects' responses toward economic disparity could be categorized into three types: 1) critical response (structural), 2) naive individualistic response and 3) fatalistic response. Most subjects provided naive individualistic response. Result of cross tabulation test showed that authorianism had negative correlation with critical response but had positive correlation with naive individualistic response. Materialism had positive correlation with naive individualistic response. Authorianism and materialism were not related to fatalistic response.
\end{abstract}

Keywords: authoritarianism; critical conscience; economic disparity; materialism; naive individualistic conscience

\begin{abstract}
Abstrak. Penelitian ini bertujuan untuk mengetahui bagaimana anak muda memahami persoalan kesenjangan ekonomi dan apakah gagasan mengenai persoalan tersebut berhubungan dengan kecenderungan otoritarianisme dan materialisme. Penelitian dilakukan pada kelompok mahasiswa berusia 18 - 30 tahun. Jumlah subjek yang terlibat adalah 295 orang. Metode yang digunakan adalah survei dengan menggunakan pertanyaan terbuka mengenai perasaaan dan pikiran mereka terkait kesenjangan ekonomi. Subjek juga mengisi skala otoritarianisme dan materialisme. Hasil penelitian menunjukkan tanggapan para mahasiswa mengenai kesenjangan dapat dikelompokkan menjadi tiga jenis tanggapan: 1) tanggapan kritis (struktural), 2) tanggapan naif individualistik dan 3) tanggapan fatalistik. Sebagian besar tanggapan mengarah pada tanggapan naif individualistik. Hasil uji tabulasi silang menunjukkan bahwa otoritarianisme berhubungan negatif dengan tanggapan kritis dan berhubungan positif dengan tanggapan naif. Materialisme berhubungan positif dengan tanggapan naif. Baik otoritarianisme maupun materialisme tidak berhubungan dengan tanggapan fatalistik.
\end{abstract}

Kata kunci: kesadaran kritis; kesadaran naif individualistik; kesenjangan ekonomi; materialisme; otoritarianisme

\footnotetext{
${ }^{1}$ Korespondensi mengenai isi artikel ini dapat

dilakukan melalui didiksuryo@yahoo.co.id

2 atau melalui dickyh@ugm.ac.id 
Kesenjangan ekonomi merupakan masalah besar yang dihadapi, baik oleh negara maju maupun negara berkembang seperti Indonesia. Studi pada negara-negara maju menunjukkan tingkat kesetaraan ekonomi ditentukan oleh kebijakan pemerintah yang lebih pro pemerataan (jaminan sosial, pajak progresif, pemberian dana tunai dan non tunai pada kelompok miskin, layanan kesehatan publik, dan aktivitas-aktivitas pemerintah untuk penguatan sosialekonomi) (Brady, 2009). Strategi tersebut cenderung lebih dipilih ketika lebih banyak aktor-aktor politik yang berideologi kesetaraan berada di dalam pemerintahan maupun parlemen, dan di luar pemerintahan didukung oleh koalisi sipil egalitarian. Aktor politik di tingkat parlemen maupun koalisi sipil mendorong pemerintah untuk merancang dan melaksanakan kebijakan-kebijakan yang mengarah pada upaya pemerataan.

Apakah pemerintah memilih strategi pro pemerataan atau memilih efek penetesan ke bawah (trickle down effect) sebagai cara menangani persoalan kemiskinan dan kesenjangan, bergantung pada gagasan-gagasan mengenai kemiskinan dan kesenjangan yang berkembang di dalam masyarakat. Para pemain politik tersebut memperoleh gagasan dan dukungan dari gagasan maupun kehendak yang hidup di dalam masyarakat. Strategi pro pemerataan lebih banyak dipilih ketika masyarakat cenderung berasumsi bahwa bahwa kemiskinan lebih banyak ditentukan oleh distribusi kekuasaan dan kekayaan yang tidak adil (atribusi struktural) ketimbang oleh oleh sebab-sebab individual yang melekat pada diri orang miskin (atribusi individual) (Brady, 2009; Royce, 2009).

\section{Atribusi sebab-sebab kemiskinan}

Studi mengenai bagaimana individu memahami kemiskinan dan ketidaksetaraan memperlihatkan adanya tiga jenis atribusi mengenai sebab-sebab kemiskinan dan kesenjangan, yakni atribusi struktural, atribusi individual dan atribusi fatalistik (Kluegel \& Smith, 1981). Atribusi struktural merujuk pada sebabsebab yang bersifat sistemik dan sosial seperti distribusi kesempatan untuk bekerja, kesempatan untuk belajar, dominasi kekuasaan maupun perbedaan perlakuan terhadap berbagai kelompok sosial ekonomi di dalam masyarakat. Di dalam atribusi struktural ini kemiskinan dan kesenjangan dipahami sebagai suatu kekeliruan yang melekat pada sistem. Berbeda dengan atribusi individualistik yang cenderung memandang kemiskinan sebagai akibat dari kesalahan individual. Seorang menjadi kaya atau miskin akibat dari kemalasannya bekerja, kecerobohannya mengelola keuangan dan ketiadaan hasrat untuk maju. Dalam pemahaman ini orang miskin itu sendirilah yang bersalah atas keadaan yang dialaminya. Atribusi fatalistik mengacu pada sebab-sebab yang bersifat tak dapat dikendalikan. Orang menjadi miskin atau kaya karena keberuntungan dan ketidakberuntungan yang dialaminya atau karena kehendak Tuhan dan takdir yang harus disandangnya.

Atribusi struktural akan mengarahkan orang pada dukungan terhadap program-program pemerintah yang bersifat pro pemerataan. Dalam studi mengenai sebab-sebab kehidupan menggelandang, atribusi struktural berkorelasi positif dengan kecenderungan untuk mendukung rencana kenaikan pajak dan subsisdi perumahan bagi kaum miskin, sedangkan atribusi individualistik cenderung mendukung kebijakan yang bersifat mengurangi layanan sosial terhadap kaum gelandangan (Lee, Jones, \& Lewis, 1990). Atribusi individualistik juga cenderung kurang mendukung program pemerintah untuk membantu kelompok miskin serta memandang para penerima 
bantuan pemerintah secara negatif (Niemelä, 2008). Dukungan masyarakat pada program-program pemertaan inilah yang berperan penting dalam keberhasilan suatu negara untuk mengurangi tingkat ketidaksetaraan dalam masyarakat (Brady, 2009).

Penelitian mengenai persoalan ini di Indonesia pernah dilakukan oleh Bank Dunia pada tahun 2014 (Indrakesuma, Janz, \& Wai-Poi, 2015). Salah satu pertanyaan survei yang relevan dengan penelitian ini adalah tentang sebab-sebab kemiskinan. Sebagian besar memandang kemiskinan disebabkan oleh kemalasan (34 $\%)$, keadaan keluarga yang miskin (22\%), nasib buruk (16 \%) kurangnya pendidikan (11 \%), kurangnya kemampuan (9\%), lingkungan yang tidak mendukung $(6 \%)$ serta kecacatan fisik (3\%). Hasil ini jika diterjemahkan ulang dalam tiga jenis atribusi strukturalistik, individualistik dan fatalistik menunjukkan kecenderungan yang kuat terhadap atribusi individualistik (kemalasan, kurangnya pendidikan, dan kemampuan atau bakat, total $64 \%$ ). Atribusi strukturalistik hanya $28 \%$ (latar belakang keluarga dan lingkungan yang tidak mendukung) dan paling rendah adalah atribusi fatalistik (nasib buruk dan kecacatan fisik.

Studi ini dimaksudkan untuk memperdalam temuan di atas dengan memeriksa bagaimana orang memikirkan persoalan kemiskinan dan kesenjangan. Pertanyaan dasarnya adalah bagaimana kaum muda memahami persoalan kemiskinan dan kesetaraan. Fokus pada kaum muda didasarkan pada alasan bahwa merekalah di kemudian hari akan bertanggung jawab dalam proses-proses politik yang akan menentukan bagaimana kemiskinan dan ketidaksetaraan akan ditangani.

\section{Tingkat perkembangan sosial politik}

Selain alasan praktis tersebut, secara teoretis kaum muda sedang dalam proses pergeseran perhatian dan cara berfikir dari egosentris yang berpusat pada diri sendiri ke arah sosiosentris yang memusatkan perhatian pada masyarakat dan sistem sebagai penentu keadaan anggota masyarakat (Flanagan et al., 2014; Flanagan \& Tucker, 1999; Leahy, 1990). Pada usia remaja ketika individu mulai berpikir secara formal operasional, remaja mulai dapat melihat dirinya sendiri dalam perspektif orang lain dan secara khusus melihat dirinya dalam perspektif sistem sosial kemasyarakatan. Proses ini sering disebut sebagai desentrasi. Kemampuan ini memungkinkan mereka untuk melihat keadaan kemiskinan dalam perspektif strukturalistik dan meninggalkan perspektif individualistik.

Perubahan dari perspektif individual menuju perspektif struktural dalam studi psikologi dapat dipahami sebagai bagian dari proses perkembangan sosial politik atau sosio-political development (SPD) (Baker \& Brookins, 2014; Watts, Williams, \& Jagers, 2003). Model SPD ini mengikuti gagasan perkembangan kesadaran kritis dari pendidikan kaum tertindas yang dikembangkan di Brasil pada tahun 1960an (Freire, 1993, 2005). Sepanjang masa hidupnya seseorang memiliki kemungkinan untuk mengembangkan tiga gagasan kesadaran sosial politik. Gagasan paling awal dan paling primitif adalah kesadaran magis, yakni kecenderungan untuk melihat kenyataan sosial politik sebagai kenyataan yang bersifat terberi, pasti dan tak dapat diubah. Kondisi sosial politik yang dihadapi dipandang sebagai nasib. Dalam studi mengenai atribusi kemiskinan model pemahaman magis ini menyerupai perspektif fatalistik. Gagasan kedua adalah kesadaran naif individualistik. Dalam pemahaman ini kondisi sosial yang dialami individu 
dipahami sebagai disebabkan oleh si individu sendiri. Kemiskinan adalah akibat dari perbuatan dan ketidakmampuan individu. Pemahaman ini menyerupai perspektif individualistik. Tindakan yang dipikirkan adalah pengembangan diri atau individu. Gagasan ketika adalah kesadaran kritis. Dalam tingkat kesadaran ini orang mulai memahami pengalaman individu sebagai bagian dari segala hal yang terjadi di dalam lingkungan sosial politiknya. Kemiskinan disebabkan oleh ketidakadilan dan penindasan. Aktivitas yang dilakukan untuk mengatasinya menyasar pada perubahan sistem dan relasi-relasi sosial yang membatasi kehidupan seseorang (Freire, 1993). Perkembangan kesadaran sosial politik ini seringkali juga disebut dengan perkembangan kesadaran kritis dengan mengacu pada tahap akhir kesadaran sosial politik.

Otoritarianisme, materialisme dan kesadaran kritis

Tantangan terbesar masyarakat sipil dewasa ini adalah proses-proses yang menempatkan manusia hanya sebagai sumber tenaga kerja dan konsumen. Konsekuensi psikologis yang paling kentara dari proses-proses tersebut adalah kecenderungan materialisme, yaitu kecenderungan untuk menempatkan pemerolehan kekayaan (kekuatan finansial) dan konsumsi kemewahan sebagai hal yang utama dalam kehidupan (Belk \& Belk, 1985; Kasser \& Ryan, 1993; Richins, 2004).

Remaja yang materialistik dan memiliki tingkat altruisme rendah cenderung mengatribusikan ketidaksetaraan pada sebab-sebab individualistik (Flanagan \& Tucker, 1999). Mereka lebih meyakini bahwa masyarakat mereka telah berlaku adil dan memandang program pemerintah dalam pengentasan kemis- kinan akan menghasilkan ketergantungan. Mereka juga cenderung berasal dari keluarga yang lebih menekankan nilainilai self-reliance ketimbang nilai-nilai belas kasih (compassion). Orang dengan orientasi kuat pada materialisme dan konsumerisme cenderung menafsirkan ketidaksetaraan dalam kerangka keadilan ekuiti yang memandang perolehan seseorang bergantung pada sumbangan yang diberikan (Skitka, 2003) dan cenderung memandang ketidaksetaraan sebagai hal yang normal (Caruso, Vohs, Baxter, \& Waytz, 2013).

Otoritarianisme yang tumbuh dalam masyarakat juga mengancam kesadaran kritis masyarakat. Otoritarianisme merupakan kecenderungan untuk bersikap submisif terhadap otoritas, bermoral secara konvensional atau heteronomi dan bersikap agresif terhadap orang-orang yang melanggar norma otoritas (Adorno, Frenkel-Brunsivik, Levinson, \& Sanford, 1950; Altemeyer, 2006; Duckitt, 2001). Orang otoritarian cenderung berorientasi mendominasi orang lain (Sibley, Wilson, \& Duckitt, 2007), namun ketika berhadapan dengan orang yang lebih kuat akan cenderung menempatkan diri sebagai pengikut dan bersikap toleran pada perilaku tidak etis pemimpinnya (Son Hing, Bobocel, Zanna, \& Mcbride, 2007). Mereka memiliki pengetahuan politik yang rendah dan tidak berminat mempelajari politik. Mereka kurang memperhatikan peristiwaperistiwa yang berkaitan dengan persoalan-persoalan kesetaraan dan hakhak sipil, tetapi amat berminat mengikuti peristiwa-peristiwa yang berkaitan dengan pelanggaran norma konservatif (Peterson, Duncan, \& Pang, 2002). Kecenderungan otoritarianisme berkorelasi positif dengan prasangka terhadap kelompok-kelompok dalam masyarakat yang dianggap berbahaya, lebih rendah secara sosial, maupun kelompok-kelompok yang 
dipandang menentang sistem (Cantal, Milfont, Wilson, \& Gouveia, 2015) dan berkorelasi negatif dengan nilai-nilai humanitarian-egalitarian (Oyamot, Borgida, Fisher, \& Fisher, 2006).

Hasil-hasil penelitian di atas menunjukkan aspirasi materialistik dan kecenderungan otoritarianisme mungkin berperan penting terhadap kesadaran kritis masyarakat mengenai persoalan kemiskinan dan ketidaksetaraan. Kecenderungan nilai-nilai materialistik mengarahkan orang pada gagasan individualistik dan meritokratik yang cenderung membuat orang menyalahkan kelompok miskin sebagai orang yang malas dan bodoh. Mereka melupakan kenyataan bahwa proses-proses akumulasi kekayaan secara kapitalistik telah menghasilkan perbedaan kekuasaan antara orang miskin dan kaya yang akan cenderung melestarikan ketimpangan. Nilai-nilai otoritarianisme yang tumbuh di dalam kehidupan sehari-hari masyarakat dari berbagai penelitian terbukti berperan penting menghambat upaya-upaya untuk melindungi kebebasan dan kesetaraan politik. Orang-orang otoritarian cenderung membenarkan atau menjustifikasikan sistem yang ada (Jost \& Hunyady, 2005). Mereka mengacu pada apa yang disebut sebagai tatanan alamiah, seolah-olah kenyataan saat ini adalah nasib yang harus diterima dan bersikap resisten terhadap perubahan. Apakah mungkin otoritarianisme juga akan berperan membentuk gagasan-gagasan naif maupun magis di dalam persoalan kemiskinan dan ketidaksetaraan? Penelitian ini hendak mengetahui peran kecenderungan otoritarianisme maupun nilai-nilai materialistik terhadap kesadaran kritis mengenai kemiskinan dan ketidaksetaraan.

\section{Metode}

Studi ini berupaya memahami bagaimana orang awam, khususnya kaum muda memahami persoalan ketidaksetaraan ekonomi atau kesenjangan kaya dan miskin. Fokus utamanya adalah untuk menemukan gambaran pemahaman mereka mengenai kesenjangan ekonomi. Apakah gambaran mereka menyerupai hasil-hasil penelitian sebelumnya yang menunjukkan adanya tiga model dasar tentang bagaimana kemiskinan terjadi, yaitu atribusi pada kemampuan individual, atribusi sistemik struktural dan atribusi pada nasib? Kedua, apakah pemahaman mereka mengenai masalah kesenjangan ekonomi akan berhubungan dengan kecenderungan otoritarianisme maupun materialisme?

Untuk mendapatkan gambaran pemahaman tentang kesenjangan ekonomi tersebut peneliti mempergunakan pertanyanyaan terbuka yang mengacu pada hasil-hasil studi sebelumnya (Flanagan et al., 2014; Flanagan \& Tucker, 1999; Leahy, 1990). Pertanyaan yang diajukan pada mereka adalah: Apa yang mereka rasakan dan pikirkan tentang kesenjangan ekonomi atau perbedaan antara orang kaya dan miskin?

Untuk mengetahui peran nilai otoritarianisme dan materialisme, peneliti meminta responden untuk menjawab skala otoritarianisme dan skala materialisme. Skala otoritarianisme disusun oleh peneliti sendiri dengan mengacu pada konsep otoritarianisme sayap kanan dari Altemeyer (2006) yang terdiri dari tiga aspek: sikap tunduk dan taat pada otoritas, sikap moral konvensional, dan sikap agresif terhadap pelanggaran norma. Keseluruhan aitem berjumlah 12 aitem dengan 4 aitem untuk masing-masing aspek. Metode penskalaan yang digunakan adalah metode skala likert dengan 5 pilihan jawaban. Makin tinggi 
angka yang idpilih menunjukkan responden makin menyetujui isi aitem pernyataan. Sor total berkisar antara 12 hingga 60. Uji coba alat ukur dengan 98 subjek menunjukkan nilai reliabilitas sebesar 0,876 . Skala materialisme disusun dengan mengacu pada dua aspek materialisme yaitu aspirasi terhadap kekayaan dan kecenderungan konsumerisme. Skala ini berisi 8 aitem pernyataan, dengan metode penskalaan likert lima pilhan jawaban. Makin tinggi angka yang dipilih menunjukkan penjawab makin menyetujui pernyataan aitem. Skor total berkisar antara delapan hingga 40. Uji coba alat ukur dengan 98 subjek menunjukkan nilai reliabilitas sebesar 0,697.

Pengambilan data dilakukan pada bulan Maret hingga April tahun 2019. Ada 295 mahasiswa yang terlibat dalam penelitian ini dengan mengisi kuesioner skala otoritarianisme, skala materialisme dan kuesioner pertanyaan terbuka mengenai kesan dan pemikiran mereka tentang kesenjangan ekonomi. Mahasiswamahasiswa yang terlibat berasal dari fakultas Psikologi dan fakultas Pendidikan dari dua universitas swasta dan satu universitas negeri di Yogyakarta. Data demografis para responden tersebut dapat dilihat pada Tabel 1.

\section{Analisis data dan uji reliabilitas koding}

Analisis data dilakukan secara bertahap.

Tahap pertama adalah pembacaan

Tabel 1.

Data Demografi Subjek Penelitian

\begin{tabular}{lll}
\hline \multicolumn{1}{c}{ Data Demografi } & & \multicolumn{1}{c}{ Persentase } \\
\hline Jenis kelamin & Laki-laki & $73(24,74 \%)$ \\
& perempuan & $222(75,25 \%)$ \\
\hline Usia & Rerata & 20,22 tahun \\
& rentang & $18-30$ tahun \\
\hline Semester & 2 & 1 \\
& 4 & 160 \\
& 6 & 134 \\
\hline
\end{tabular}

jawaban secara keseluruhan untuk menangkap kesan-kesan dan gagasan utama yang ada pada jawaban responden. Langkah berikutnya adalah mulai membuat koding terbuka pada semua jawaban responden. Hasil koding sementara kemudian saling dibandingkan untuk menangkap kategori-kategori yang lebih besar. Proses pengkodean dilakukan dengan bantuan alat analisis data kualitatif MAXQDA versi 12. Peneliti melakukan uji reliabilitas koding dengan meminta satu orang lain untuk melakukan pengkodean dengan menggunakan kategori-kategori dasar yang ditemukan oleh peneliti. Hasil uji reliabilitas pada 200 sampel pertama menunjukkan adanya kecocokan sebesar $80,6 \%$.

Untuk mengetahui peran variabel otoritarianisme dan materialisme peneliti melakukan uji hubungan variabel nominal Chi-Square antara tingkat materialisme dan otoritarianisme dengan jawaban terhadap persoalan kesenjangan yang dibagi dalam tiga kategori besar yang mengacu pada tiga tingkat kesadaran kritis yaitu kategori kesadaran kritis (perspektif strukturalis), kategori kesadaran naif individualis (perspektif individual) dan kategori kesadaran magis (perspektif fatalistik). Peneliti membagi tingkat materialisme dan tingkat otoritarianisme dalam dua kelompok besar dengan menggunakan analisis kluster. Kelompok otoritarianisme tinggi terdiri dari 155 orang dengan nilai rerata 57,02. Kelompok otoritarianisme 
rendah terdiri dari 140 orang dengan nilai rerata 40,31. Kelompok materialisme tinggi terdiri dari 144 orang dengan nilai rerata sebesar 35,41, sedangkan kelompok rendah terdiri dari 151 orang dengan nilai rerata sebesar 22,77.

\section{Hasil}

Kesan dan pemikiran tentang kesenjangan ekonomi

Tanggapan responden terhadap kesenjangan ekonomi secara umum dapat terbagi menjadi tiga kelompok jawaban. Kelompok pertama mengacu pada kesadaran kritis yang terekspresi dengan ungkapan-ungkapan bahwa kesenjangan tersebut bersifat tidak adil serta upaya menjelaskan kesenjangan dengan mengacu pada sebab-sebab struktural. Kelompok kedua merupakan jawaban yang mengacu kesadaran naif individualistik yang terdiri dari jawaban berisi: rasa simpati dan ingin membantu orang miskin, tuntutan dan kecaman terhadap orang kaya, perasaan termotivasi untuk menjadi kaya, dan pembenaran terhadap kesenjangan dengan mengacu pada prinsip meritokarasi (kerja keras, usaha, pilihan individu, cara mengelola keuangan). Kelompok ketiga mengacu pada kesadaran magis atau fatalistik yang terdiri dari dua jawaban yaitu, pembenaran / justifikasi kesenjangan berdasarkan pemahaman fatalistik (kesenjangan ekonomi adalah suatu kepastian, takdir atau jalan hidup yang sudah digariskan, dan nasib baik atau nasib buruk) serta kecenderungan untuk mensyukuri keadaan. Pengelompokan jawaaban tersebut didasarkan pada pengkodean tingkat kesadaran kritis dari Smith (1975) yang mengacu pada gagasan Paulo Freire. Tabel 2 merangkum tanggapan mengenai kesenjangan sosial.

Jawaban yang mengacu pada rasa keadilan umumnya berupa jawaban

Tabel. 2

Kata Kunci, Komponen dan Dimensi Model Pemahaman Kritis

\begin{tabular}{|c|c|c|c|c|c|c|}
\hline Kata kunci & Komponen & $\mathbf{N}$ & $\%$ & Dimensi & $\mathbf{N}$ & $\%$ \\
\hline $\begin{array}{l}\text { Itu tak adil; saya } \\
\text { merasa marah }\end{array}$ & Rasa keadilan & 69 & 23,39 & $\begin{array}{l}\text { Kesadaran } \\
\text { Kritis }\end{array}$ & 89 & 30,17 \\
\hline $\begin{array}{l}\text { Sistem yang salah; } \\
\text { privilege; akses tak } \\
\text { merata }\end{array}$ & $\begin{array}{l}\text { Pemahaman } \\
\text { struktural }\end{array}$ & 28 & 9,49 & & & \\
\hline $\begin{array}{l}\text { Iba, kasihan, ingin } \\
\text { membantu }\end{array}$ & $\begin{array}{l}\text { Simpati pada } \\
\text { orang miskin }\end{array}$ & 109 & 36,95 & $\begin{array}{c}\text { Kesadaran } \\
\text { Naif }\end{array}$ & 202 & 68,47 \\
\hline $\begin{array}{l}\text { Kerja keras, usaha } \\
\text { maksimal, }\end{array}$ & $\begin{array}{l}\text { Justifikasi } \\
\text { meritokrasi }\end{array}$ & 76 & 25,76 & & & \\
\hline $\begin{array}{l}\text { Merasa iri dan } \\
\text { ingin menjadi } \\
\text { seperti itu }\end{array}$ & $\begin{array}{l}\text { Ingin menjadi } \\
\text { kaya }\end{array}$ & 36 & 12,20 & & & \\
\hline $\begin{array}{l}\text { Sombong; tak } \\
\text { peduli; jika saja } \\
\text { mau membantu }\end{array}$ & $\begin{array}{l}\text { Tuntutan dan } \\
\text { kecaman pada } \\
\text { orang kaya }\end{array}$ & 34 & 11,52 & & & \\
\hline $\begin{array}{l}\text { Keseimbangan; } \\
\text { takdir; nasib }\end{array}$ & $\begin{array}{l}\text { Pembenaran } \\
\text { fatalistik }\end{array}$ & 40 & 8,14 & $\begin{array}{c}\text { Kesadaran } \\
\text { Magis }\end{array}$ & 60 & 20,34 \\
\hline Syukur & $\begin{array}{l}\text { Rasa syukur } \\
\text { karena tidak } \\
\text { miskin }\end{array}$ & 24 & 13,56 & & & \\
\hline
\end{tabular}


singkat yang berisi tanggapan kemarahan terhadap keadaan atau perasaan tak berdaya.

"Kasihan dan terkadang marah, kenapa di dunia ini tidak adil, ada yang kaya dan miskin" (PST004)

"Terlihat kesenjangan yang begitu terasa. Kadang hidup tidak adil saat seseorang yang selalu miskin meskipun sudah berusaha" (PST052)

Rasa ketidakadilan itu juga terungkap dalam bentuk-bentuk kritik terhadap sistem ekonomi dan pemeritntahan yang ada.

"Jika ada sebagian orang yang kaya sekali dan sebagaian sangat miskin pasti ada yang salah dengan sistem yang ada di masyarakat" (PSD076)

"Menurut saya agar ketimpangan ekonomi dapat diminimalisisr harus diterapkan sistem sosialisme seperti yang diterapkan oleh negara-negara Skandinavia" (BNY106)

Tanggapan di atas memperlihatkan bahwa kaum muda mulai memikirkan bahwa kesenjangan ekonomi dapat menginformasikan kesalahan pada sistem ekonomi dan sosial yang ada.

Beberapa jawaban yang lain merujuk pada kelas sosial, hak istimewa orang kaya dan dominasi ekonomi sebagai sumber kesenjangan.

"Karena yang kaya bisa berkuasa atas kekayaannya yang dia miliki dan yang miskin sering dipandang remeh oleh masyarakat" (PST046)

“Tentunya sedih ketika melihat orang kaya berpikir bahwa mereka telah bekerja keras, menganggap bahwa orang yang miskin adalah hasil kemalasan, padahal apa yang mereka sebut "kerja keras" adalah hasil dari priviledge yang mereka dapat dari orang tua mereka" (BNY079)

"Saya merasa sedikit takut melihat masa depan saya apakah bisa menjadi kaya kelak. Saya berpikir sistem ekonomi liberal memang menuntut persaingan terbuka dan memberikan peluang terciptanya orang kaya- orang miskin" (A174)

Tanggapan yang paling menonjol dari kesadaran naif adalah rasa simpati terhadap penderitaan orang miskin yang seringkali diikuti oleh keinginan untuk membantu.

"Jelas saya merasa sangat sedih. Terlebih saat orang yang sangat berkecukupan tersebut memikirkan ego dan emosinya sendiri. Sempat terpikir bagaimana caranya agar saya menjadi orang penting yang berperan dalam negara dan bagaiman bisa kita meringankan dan mengurangi kemiskinan" (BNY013)

Rasa simpati pada orang miskin itu seringkali kemudian diikuti oleh tuntutan dan kecaman terhadap orang kaya.

"Apa yang saya rasakan melihat ketimpangan ekonomi ini adalah sedih dan sedikit iri. Beberapa orang bahkan tidak tahu akan makan apa untuk keesokan hari. Dan ada juga mereka yang membuang untuk merasakan makanan dengan emas dan komposisi mahal di dalamnya" (BNY050)

Apa yang menonjol dari pernyataanpernyataan anak muda adalah percampuran perasaan, di satu sisi merasa simpati pada orang miskin dan ingin 
membantunya dan sekaligus merasa jengkel terhadap orang kaya yang tidak mau mebantu, namun di sisi lain juga merasakan iri hati terhadap kemakmuran orang kaya.

“Tetapi di sisi lain saya merasa kurang habis pikir ketika orang-orang kaya mampu membeli mobil sport seharga milyaran, barang-barang branded, hidup hura-hura menghamburkan uang demi kesenangannya. Kadang saya juga memikirkan ingin menjadi orang kaya raya agar bisa mendapatkan segala yang saya inginkan" (A176)

Bentuk paling jelas bersifat naif dari tanggapan ini tampak pada perasaan termotivasi untuk menjadi kaya. Mereka lebih memikirkan bagaimana mereka dapat menjadi kaya seperti yang mereka lihat ketimbang merasakan kesenjangan sebagai hal yang menyakitkan atau tak adil.

"Yang saya pikirkan ada sebagian orang memiliki sangat banyak memotivasi saya untuk menjadi orang yang lebih baik lagi dan juga disiplin tentunya" (PST041)

Orang yang naif juga cenderung untuk memandang kemiskinan sebagai hal disebabkan oleh perbuatan korban sendiri. Mereka memandang kesenjanagan sebagai kewajaran karena orang-orang miskin itu tidak mau berusaha memperbaiki hidupnya.

"Miskin: yang saya rasakan mungkin lebih kepada orang miskin gampang mudah sekali menyerah, dari pemikiran saya jika saja orang miskin mau untuk berusaha lebih, mungkin saja kehidupannya akan lebih makmur" (PST002)
“Turut prihatin dengan yang nasibnya kurang beruntung tetapi mereka harus berusaha supaya memiliki sangat banyak uang dan jangan gengsi melakukan perkerjaan apa pun asal halal" (PST011)

Tingkat kesadaran magis menekankan pada sikap pasrah terhadap keadaan dan keyakinan bahwa apa yang terjadi adalah di luar kendali diri sendiri. Sebagian dari mereka memandang kemiskinan dan kesenjangan adalah kepastian hidup. Keseimbangan dunia mempersyaratkan adanya orang miskin dan orang kaya.

"Saya merasa hal tersebut adalah hal
yang wajar karena di dunai ini
semuanya diciptakan berpasang-
pasangan dan sesuai timbangannya,
seperti ada kebaikan-keburukan, kuat-
lemah dan semacamnya" (BNY060)

Kemiskinan dan kekayaan yang yang dialami oleh seseorang adalah nasib yang sudah digariskan.
"Semua orang mempunyai jalan hidup masing-masing sehingga ketika ada orang yang mempunyai dan tidak, yang penting berdoa, usaha, niat dan syukuri apa yang ada" (PST045)

Tanggapan yang menyertainya adalah rasa syukur atau harapan bahwa orang miskin juga dapat bersyukur.

"Perasaan: sedih karena banyak yang masih menganggap diri mereka miskin dan tidak bersyukur, pikiran: bagaimana cara mengubah mindset orang miskin bahwa mereka bisa bersyukur dengan apa yang mereka miliki, ketika tidak bersyukur selalu merasa kurang" (A134) 
Melihat kemiskinan yang dialami orang lain juga memungkinkan mereka untuk membandingkan keadaan diri sebagai lebih baik.

“Namun kita dapat belajar bahwa kita hidup harus melihat ke bawah (orang miskin) agar tidak sombong dan tetap bersyukur" (PST014)

"Sebagai cerminan agar lebih bersyukur karena masih banyak orang yang di bawah" (PST027)

Hubungan otoritarianisme, materialisme dengan kesan dan pemikiran mengenai kesenjangan

Hasil analisis tabulasi silang pada Tabel 3 memperlihatkan kecenderungan otoritarianisme behubungan negatif dengan tanggapan kritis dan berhubungan positif dengan tanggapan naif. Aspirasi materialistik berhubungan positif dengan kecenderungan tanggapan naif individualistik. Kecenderungan otoritarianisme dan materialisme tampaknya memiliki peran kuat terhadap tanggapan terhadap persoalan kesenjangan. Orang otoritarian cenderung memandang persoalan kesenjangan sebagai persoalan individualistik. Kemiskinan adalah akibat kelemahan individu. Orang otoritarian tidak merasakan hal itu sebagai ketidakadilan karena mereka tidak memandangnya dalam perspektif struktural. Baik otoritarianisme maupun materialisme dalam penelitian ini tidak berhubungan dengan kecenderungan fatalistik.

\section{Diskusi}

Hasil penelitian memperlihatkan bahwa variasi tanggapan kaum muda terhadap kesenjangan lebih banyak berpusat pada tanggapan yang bersifat naif individualistik. Sebagian besar dari mereka tidak memahami bahwa kemiskinan dapat menginformasikan mengenai kesalahan sistem. Ada kemungkinan bahwa sebagian besar dari mereka tidak melihat kenyataan sosial sebagai suatu hal yang bersifat dinamis terkait erat dengan kekuatan-kekuatan sosial di luar diri yang membentuknya. Variasi jawaban yang ditemukan kurang lebih mengikuti temuan-temuan sebelumnya (Flanagan et al., 2014; Flanagan \& Tucker, 1999; Kluegel \& Smith, 1981; Leahy, 1990). Keserupaan dengan temuan dari wilayah kebudayaan yang berbeda mungkin dapat menjadi petunjuk tentang universalitas gagasan mengenai kemiskinan.

Penelitian ini juga memperlihatkan dengan jelas bahwa ideologi yang bersifat menjustifikasikan tata sosial yang ada

Tabel 3.

Hubungan Otoritarianisme, Materialisme dengan Kecenderungan Tanggapan Terhadap Kesenjangan

\begin{tabular}{llllllll}
\hline & & \multicolumn{2}{l}{ Otoritarianisme } & $\begin{array}{l}\text { Chi- } \\
\text { square }\end{array}$ & Materialisme & $\begin{array}{l}\text { Chi- } \\
\text { square }\end{array}$ \\
\hline & & Tinggi & Rendah & $(\mathrm{p})$ & Tinggi & Rendah & $(\mathrm{p})$ \\
\hline Kritis & 0 & 119 & 87 & 7,475 & 106 & 100 & 1,909 \\
\hline Naif & 1 & 36 & 53 & $(0,006)$ & 38 & 51 & $(0,167)$ \\
\hline & 0 & 41 & 52 & 3,895 & 35 & 58 & 6,793 \\
\hline Magis & 1 & 114 & 88 & $(0,048)$ & 109 & 93 & $(0,09)$ \\
\hline & 0 & 121 & 114 & 0,514 & 116 & 119 & 0,139 \\
\hline
\end{tabular}


memiliki peran penting dalam pembentukan gagasan mengenai kemiskinan dan kesenjangan ekonomi (Jost \& Hunyady, 2005). Baik kecenderungan materialisme maupun otoritarianisme berfungsi untuk mengarahkan perhatian seseorang lebih kepada faktor-faktor individual penyebab kemiskinan. Kecenderungan otoritarianisme menekankan pada sikap tunduk terhadap gagasan dan kebenaran yang bersifat konvensional. Otoritarianisme mendorong orang untuk memperkuat sistem sosial yang ada dan menghalangi tumbuhnya cara berpikir kritis yang mempertanyakan keberadaan sistem. Kecenderungan materialisme memperkuat hal tersebut, karena materialisme lebih banyak mendorong orang untuk memperhatikan diri sendiri ketimbang memperhatikan orang lain (Caruso et al., 2013). Kecenderungan materialisme memperkuat keyakinan bahwa distribusi sumber daya dapat dilakukan secara baik oleh sistem pasar. Apa yang dapat diperoleh seseorang dalam hidupnya tergantung pada kemampuan dan kemauan individu.

\section{Kesimpulan}

Hasil penelitian ini memperlihatkan kecenderungan umum untuk memandang persoalan kemiskinan dan kesenjangan sebagai persoalan individual. Kecenderungan tersebut diperkuat oleh aspirasi materialistik dan sistem nilai yang bersifat otoritarian. Sebagian kecil dari kaum muda yang diteliti mampu memperlihatkan perpsektif yang bersifat lebih struktural. Perspektif tersebut mengikuti tumbuhnya perasaan ketidakadilan. Baik rasa ketidakadilan maupun perpsektif struktural dapat menjadi sarana untuk lebih memperhatikan keberadaan persoalan kesenjangan. Orang yang merasakan kemiskinan sebagai ketidakadilan dan memandang persoalan dalam perspektif struktural lebih mungkin untuk terlibat dalam aktivitas sosial-politik yang mengarah pada kebijakan propemerataan.

Saran

Penelitian selanjutnya mungkin perlu untuk melihat bagaimana tanggapan ketidakadilan dan perspektif struktural dapat ditumbuhkan.

\section{Kepustakaan}

Adorno, T. W., Frenkel-Brunsivik, E., Levinson, D. J., \& Sanford, R. N. (1950). The authoritarian personality. New York: Harper \& Row.

Altemeyer, B. (2006). The authoritarian. Winnipeg, Canada: Departement of Psychology University of Manitoba.

Baker, A. M., \& Brookins, C. C. (2014). Toward the development of a measure of sociopolitical consciousness: Listening to the voices of Salvadoran youth. Journal of Community Psychology, 42(8), 10151032. doi: $10.1002 / j$ cop. 21668

Belk, R. W., \& Belk, R. W. (1985). Materialism: Trait aspects of living in the material world. Journal of Consumer Research, 12(3), 265-280.

Brady, D. (2009). Rich democracies, poor people: How politics explain poverty. New York: Oxford University Press.

Cantal, C., Milfont, T. L., Wilson, M. S., \& Gouveia, V. V. (2015). Differential effects of right-wing authoritarianism and social dominance orientation on dimensions of generalized prejudice in Brazil. European Journal of Personality, 27, 17-27. doi: 10.1002/per.1978

Caruso, E. M., Vohs, K. D., Baxter, B., \& Waytz, A. (2013). Mere exposure to money increases endorsement of free-market systems and social 
inequality. Journal of Experimental Psychology: General, 142(2), 301-306. doi: $10.1037 / \mathrm{a} 0029288$

Duckitt, J. (2001). A dual-process cognitivemotivational theory of ideology and prejudice. In M. P. Zanna (Ed.), Advances in experimental social psychology, Vol. 33, pp. 41-113). San Diego, CA, US: Academic Press.

Flanagan, C. A., Kim, T., Pykett, A., Finlay, A., Gallay, E. E., \& Pancer, M. (2014). Adolescents' theories about economic inequality: Why are some people poor while others are rich? Developmental Psychology, 50(11), 2512-2525. doi: 10.1037/a0037934

Flanagan, C. A., \& Tucker, C. J. (1999). Adolescents' explanations for political issues: Concordance with their views of self and society. Developmental Psychology, 35(5), 1198-1209. doi: 10.1037/0012$\underline{1649.35 .5 .1198}$

Freire, P. (1993). Pedagogy of the oppressed. New York: Continuum.

Freire, P. (2005). Education for critical consciousnes. London: Continuum.

Indrakesuma, T. R., Janz, E., \& Wai-Poi, M. G. (2015). A perceived divide: how Indonesians perceive inequality and what they want done about it. Diunduh dari http://documents.worldbank.org/cur ated/en/310491467987873894/A-

perceived-divide-how-Indonesiansperceive-inequality-and-what-theywant-done-about-it

Jost, J. T., \& Hunyady, O. (2005). Antecedents and consequences of system-justifying ideologies. Current Direction in Psychological Science, 14(5), 114-118. doi: 10.1111\%2Fj.0963-7214.2005.00377.x

Kasser, T., \& Ryan, R. M. (1993). A dark side of the American dream: Correlates of financial success as a central life aspiration. Journal of
Personality and Social Psychology, 65(2), 410-422. doi: 10.1037/0022$\underline{3514.65 .2 .410}$

Kluegel, J. R., \& Smith, E. R. (1981). Beliefs about stratification. Annual Review of Sociology, 7, 29-56. doi: 10.1146/annurev.so.07.080181.000333

Leahy, R. L. (1990). The development of concepts of economic and social inequality. New Directions for Child and Adolescent Development, 46, 107120. doi: $10.1002 / \mathrm{cd} .23219904608$

Lee, B. A., Jones, S. H., \& Lewis, D. W. (1990). Public beliefs about the causes of homelessness. Social Forces, 69(1), 253-265. doi: $\underline{10.1093 / \mathrm{sf} / 69.1 .253}$

Niemelä, M. (2008). Perceptions of the causes of poverty in Finland. Acta Sociologica, 51(1), 23-40. doi: $\underline{10.1177 / 0001699307086816}$

Oyamot, C. M., Borgida, E., Fisher, E. L., \& Fisher, E. L. (2006). Can values moderate the attitude of right-wing authoritarians? Personality and Social Psychology Bulletin, 32(4), 486-500. doi: $10.1177 / 0146167205278308$

Peterson, B., Duncan, L. E., \& Pang, J. S. (2002). Authoritarianism and political impoverishment: Deficits in knowledge and civic disinterest. Political Psychology, 23(1), 97-112. doi: 10.1111/0162-895X.00272

Richins, M. L., \& Mick, D. G., \& Monroe, K. B. (Eds.). (2004). The material values scale: Measurement properties and development of a short form. Journal of Consumer Research, 31(1), 209-219. doi: $10.1086 / 383436$

Royce, E. (2009). Poverty and power a structural perspective on American inequality. Lanham: Rowman \& Littlefield Publishers, Inc.

Sibley, C. G., Wilson, M. S., \& Duckitt, J. (2007). Effects of dangerous and competitive worldviews on rightwing authoritarianism and social dominance orientation over a five- 
month period. Political Psychology, 28(3), 357-371. doi: 10.1111/j.14679221.2007.00572.x

Skitka, L. J. (2003). Of different minds: An accessible identity model of justice reasoning. Personality and Social Psychology Review, 7(4), 286-297. doi: 10.1207/S15327957PSPRO704 02

Smith, W. A. (1975). Conscientizacao: an operational definition. University of Massachusetts.

Son Hing, L. S., Bobocel, D. R., Zanna, M. P., \& Mcbride, M. V. (2007). Authoritarian dynamics and unethical decision making: high social dominance orientation leaders and high right-wing authoritarian followers. Journal of Personality and Social Psychology, 92(1), 67-81. doi: 10.1037/0022-3514.92.1.67

Watts, R. J., Williams, N. C., \& Jagers, R. J. (2003). Sociopolitical development. American Journal of Community Psychology, 31, 185-194. doi: 10.1023/A:1023091024140 